Article

\title{
Iron-Stimulated Production and Antimicrobial Potential of a Novel Biosurfactant Produced by a Drilling Waste-Degrading Pseudomonas citronellolis Strain
}

\author{
Argyro Tsipa ${ }^{1,2, *}$, Konstantina Stylianou ${ }^{1}$, Maria Papalli ${ }^{1}$, Erato Papageorgiou ${ }^{3}$, Loucas Kyriakou ${ }^{1}$, \\ Ioannis Rigopoulos ${ }^{1} \mathbb{D}$, Ioannis Ioannou ${ }^{1} \mathbb{D}$ and Eftychia Pinakoulaki ${ }^{3}$ \\ 1 Department of Civil and Environmental Engineering, University of Cyprus, 75 Kallipoleos, \\ Nicosia 1678, Cyprus; stylianou.k@hotmail.com (K.S.); papalli.maria@ucy.ac.cy (M.P.); \\ kyriakou.loucas@ucy.ac.cy (L.K.); rigopoulos.ioannis@ucy.ac.cy (I.R.); ioannis@ucy.ac.cy (I.I.) \\ 2 Nireas International Water Research Centre, University of Cyprus, Nicosia 1678, Cyprus \\ 3 Department of Chemistry, University of Cyprus, Nicosia 1678, Cyprus; papageorgiou.erato@ucy.ac.cy (E.P.); \\ effiep@ucy.ac.cy (E.P.) \\ * Correspondence: tsipa.argyro@ucy.ac.cy
}

check for updates

Citation: Tsipa, A.; Stylianou, K.; Papalli, M.; Papageorgiou, E.;

Kyriakou, L.; Rigopoulos, I.; Ioannou,

I.; Pinakoulaki, E. Iron-Stimulated

Production and Antimicrobial

Potential of a Novel Biosurfactant

Produced by a Drilling

Waste-Degrading Pseudomonas citronellolis Strain. Processes 2021, 9, 686. https://doi.org/10.3390/ pr9040686

Academic Editors: Ewa Kaczorek and Wojciech Smułek

Received: 20 March 2021

Accepted: 12 April 2021

Published: 14 April 2021

Publisher's Note: MDPI stays neutral with regard to jurisdictional claims in published maps and institutional affiliations.

Copyright: (c) 2021 by the authors. Licensee MDPI, Basel, Switzerland. This article is an open access article distributed under the terms and conditions of the Creative Commons Attribution (CC BY) license (https:// creativecommons.org/licenses/by/ $4.0 /)$.

\begin{abstract}
A Pseudomonas citronellolis strain was isolated from drilling waste (DW). This strain utilizes DW as the sole energy and carbon source to produce biosurfactants (BSs). The BS produced was thermally stable, amorphous and includes a peptide structure. $\mathrm{FeSO}_{4}, \mathrm{FeCl}_{3}$ and $\mathrm{Fe}\left(\mathrm{NO}_{3}\right)_{3}$ were supplemented at various concentration levels to assess possible enhancement of BS production and DW biodegradation. The limit concentration of Fe compounds between the increase in BS formation and microbial toxicity was $0.1 \mathrm{mM}$. $\mathrm{FeCl}_{3}$ enhanced $\mathrm{DW}$ biodegradation and more than doubled the BS formation yield, determining an optimization strategy for BS production. The BS was then partially purified and used against several Gram-negative and positive multi-drug resistant bacteria (such as Klebsiella pneumoniae, Pseudomonas aeruginosa, Escherichia coli spp, Acinetobacter baumaniii, Enterococcus faecalis spp, Streptococcus pneumoniae, Staphylococcus aureus, Salmonella enterica). The minimum inhibitory concentration was defined at a range of 0.25 to $10 \mathrm{mg} / \mathrm{mL}$. The antimicrobial properties of the partially purified BS established its effectiveness and suggested a down-stream processing cost reduction, as no additional purification steps were necessary. The study could lead to a sustainable low-cost bioprocess towards a circular bioeconomy because waste, a non-expensive substrate, is used; while the BS holds great potential as a novel compound with antibiotic and disinfectant-like action, following toxicity testing with human cells.
\end{abstract}

Keywords: biosurfactant; drilling waste; iron-stimulation; characterization; antimicrobial properties

\section{Introduction}

Surfactants, which are surface active agents, are classified into two main categories: synthetic surfactants and biosurfactants. Synthetic surfactants are produced by organic chemical reactions, whereas biosurfactants are produced by biological processes of microorganisms [1]. Biosurfactants (BS) are amphiphilic molecules possessing a hydrophilic and a hydrophobic moiety [2]. BSs production has been attracting increased attention due to their low toxicity, high biodegradability, better environmental compatibility, higher selectivity, high foaming capacity, stable activity at extreme $\mathrm{pH}$, salinity and temperature, and compatibility with human skin [3,4], when compared to their synthetic counterparts. Given the different types of BS-producing microbial species and BS chemical structures, microbial surfactants are separated into four main categories: (1) glycolipids, (2) phospholipids, (3) polymeric surfactants, and (4) lipoproteins and lipopeptides [5].

Due to their exceptional properties, BSs are being increasingly used in various fields including: pharmaceutical and food industries as emulsifiers; surfactants in laundry products by detergent-producing industries; biological control agents in heavy oil spill 
mobilization for the control of oil pollution, for cleaning of oil sludge at storage facilities, as well as in the bioremediation of oil contaminated soil and (microbial) enhanced oil recovery ((M)EOR)) [6]. Interestingly, several BSs also exhibit antibacterial, antifungal, anticancer and antiviral activities, which render them appropriate candidate molecules for applications in combating many infections, viruses and diseases $[7,8]$.

Even though interest in BS research and development is increasing, these compounds are not yet industrially and financially feasible, as opposed to synthetic surfactants. One of the main reasons for this is their high production cost, which is almost 50 times that of synthetic surfactants [9]. Nevertheless, the cost can be reduced by optimizing the medium composition through statistical methods, optimizing culture conditions, using high yield BSproducing strains [10], strain improvement, or by using alternative inexpensive substrates, such as agricultural and drilling waste and wastewater. The latter is important to the overall economy of the process, as it accounts for up to $50 \%$ of the final production cost and may also lead to a reduction in expenses as regards to waste treatment [11], thereby leading to circular economy and sustainability. Therefore, low-cost or underutilized substrates, such as industrial waste, can be utilized to address this issue [12].

The safe disposal of drilling waste (DW) poses important waste management and environmental problems to the oil and gas $(\mathrm{O} \& \mathrm{G})$ industry, mainly due to the vast quantities generated and the high content of contaminants. DW is the second largest volume of waste, behind produced water, generated by the $O$ \& $G$ industry [13]. It mainly consists of hydrocarbons, leading to contamination of the natural resources. Bioremediation by biodegradation is considered as one of the primary mechanisms for the elimination of hydrocarbon pollutants from the environment. The potential for DW bioremediation may efficiently contribute to effective waste management in the $O$ \& $G$ industry. Furthermore, oil-related waste bioconversion to high added-value compounds, such as BSs, is an environmentally compatible and sustainable solution, enhancing the biodegradation process itself, while substantially reducing the production costs of BSs [14]. Well-known BSs used to enhance biodegradation of oil-contaminated sites and oil recovery are rhamnolipids from Pseudonomas spp. [15], sophorolipids from Candida spp. [16] and surfactins from Bacillus spp. [17].

Microorganisms are greatly affected by the growth conditions that prevail around them [18]. Different carbon and nitrogen sources, along with variations at $\mathrm{pH}$ and temperature, have resulted in increased yields of BSs [2]. In addition, metal supplementation was reported to be one of the critical factors required for the enhanced production of BSs [19]. Among the metal ions, Fe is the key microelement for BS production in several microorganisms, which also plays a key role in microbial metabolism [20].

Considering all the above, in the current study, a BS-producing microorganism, called Pseudomonas citronellolis, was isolated from DW. BS production by P. citronellolis will be exploited by degrading drill cutting fluid (DCF), a constituent of DW, and by supplementing different Fe compounds at different concentration levels. The BS will be characterized in principal and its antimicrobial potential will be tested against several Gram-negative and positive bacteria. To the best of author's knowledge, this is the first collection of data on antimicrobial activity of BSs extracted from a P. citronellolis strain against a wide number of bacterial pathogens.

\section{Materials and Methods}

\subsection{Microbial Enrichment Experiments}

The microorganism was isolated using $0.5 \%(v / v)$ drill cutting fluid (DCF), provided by Innovating Environmental Solutions Center (IESC Ltd., Limassol, Cyprus), 5\% (w/v) activated sludge coming from the municipal wastewater treatment plant of Limassol (Cyprus) as an inoculum, 10 times concentrated $(10 \times) \mathrm{M} 9$ minimal medium (i.e., $33.91 \mathrm{~g} \mathrm{Na}_{2} \mathrm{HPO}_{4}$, $15 \mathrm{~g} \mathrm{KH}_{2} \mathrm{PO}_{4}, 15 \mathrm{~g} \mathrm{NaCl}, 5 \mathrm{~g} \mathrm{NH}_{4} \mathrm{Cl}$ in $0.5 \mathrm{~L} \mathrm{dH}_{2} \mathrm{O}$ ) [21] and 500 times concentrated (500×) $\mathrm{MgSO}_{4}\left(12.0372 \mathrm{~g}\right.$ in $\left.100 \mathrm{~mL} \mathrm{dH} \mathrm{H}_{2} \mathrm{O}\right)$. Microbial enrichments were grown in a total volume of $50 \mathrm{~mL}$ in a $250 \mathrm{~mL}$ Erlenmeyer flask. In the flask, 10\% of the volume was M9 minimal 
medium and $0.02 \% \mathrm{MgSO}_{4}$. The total incubation period lasted 21 days, at a temperature of $30{ }^{\circ} \mathrm{C}$. Within the 21 days, $10 \%(\mathrm{v} / \mathrm{v})$ of the inoculum was transferred every 7 days to a freshly prepared media, which contained $\mathrm{M} 9$ minimal medium, $\mathrm{MgSO}_{4}$ and $0.5 \%(v / v)$ DCF. Following the total incubation period, $300 \mu \mathrm{L}$ of the microbial enrichment was spread to a Petri dish containing agar with $10 \% \mathrm{M} 9$ minimal medium, $0.02 \% \mathrm{MgSO}_{4}$ and $0.5 \%(v / v)$ DCF. The Petri dish was incubated at $30{ }^{\circ} \mathrm{C}$ for $48 \mathrm{~h}$. Following that, the culture of the Petri dish was spread to a new Petri dish, following the same procedure, until single colonies were observed. The process was repeated three times. Single colonies were then grown in liquid media containing $10 \% \mathrm{M} 9$ minimal medium, $0.02 \% \mathrm{MgSO}_{4}$ and $0.5 \%(v / v) \mathrm{DCF}$ in a total volume of $50 \mathrm{~mL}$ in a $250 \mathrm{~mL}$ Erlenmeyer flask for $24 \mathrm{~h}$ in triplicates. Microbial culture aliquots were separated and stored in $25 \%(v / v)$ glycerol at $-80^{\circ} \mathrm{C}$. Following that, the microbial cultures were centrifuged at $4000 \mathrm{rpm}$, the supernatant was discarded, and the biomass was proceeded for total DNA extraction.

\subsection{Microorganism Identification and Homology}

Total DNA was extracted from $100 \mathrm{~mL}$ microbial cultures using the DNeasy Kit (Qiagen, Düsseldorf, Germany), following the manufacturer's instructions. For identification of the microbial culture, de novo sequencing was performed (Macrogen Ltd., Amsterdam, the Netherlands). A draft genome sequence was generated by performing the following steps: (i) DNA PCR-Free Library construction (Illumina TruSeq), (ii) 150 bp PE sequencing run-2Gb data (illumina NovaSeq), (iii) de novo assembly, (iv) genome annotation. The nearest relative strains were identified by Basic Local Alignment Search Tool (BLAST) analysis against the National Center for Biotechnology Information (NCBI).

\subsection{Bacterial Culture Conditions}

Subcultures of the isolated strain were pre-grown for $24 \mathrm{~h}$ at $30^{\circ} \mathrm{C}$ and $100 \mathrm{rpm}$ (Shaking Orbital Incubator SI50, Stuart) in M9 minimal medium [21] and $\mathrm{MgSO}_{4}$ supplemented with $1 \%(v / v)$ DCF (IESC company, Limassol, Cyprus). Each experiment was conducted in three independent cultures, which were prepared by diluting the $24 \mathrm{~h}$ culture in M9 minimal medium and $\mathrm{MgSO}_{4}$ to an initial optical density (OD) of 0.1 (0.1 L culture volume) at $600 \mathrm{~nm}$ (UV-Visible Spectrophotometer, JASCO V-530 PC, Nicosia, Cyprus). In each experiment, $10 \%$ of the volume was $\mathrm{M} 9$ minimal medium and $0.02 \% \mathrm{MgSO}_{4}$. The exact recipe of the prepared M9 minimal medium and $\mathrm{MgSO}_{4}$ is described in Section 2.1. The M9 minimal medium and $\mathrm{MgSO}_{4}$ were supplemented with $1 \%(v / v)$ DCF, while varying additions of different Fe forms were further used, depending on the experiment performed (see below). Cultures were prepared using $500 \mathrm{~mL}$ conical Erlenmayer flasks, which were continuously stirred at the same conditions as pre-culture. The flasks were filled with medium up to one-fifth of their volume, to ensure sufficient oxygen availability to the microorganism.

\subsection{Effect of Iron Forms and Concentration Level on the Isolated Strain}

For every study, the pre-inoculum was prepared with $1 \%(v / v)$ DCF at M9 minimal media and $\mathrm{MgSO}_{4}$ and was left for $24 \mathrm{~h}$ at $30{ }^{\circ} \mathrm{C}$ and $100 \mathrm{rpm}$. For every experiment, the pre-inoculum was diluted to $0.1 \mathrm{OD}$. Certain concentrations of Fe of 3 different forms were added to the medium containing DCF. The different Fe compounds used in this study were: $\mathrm{FeSO}_{4}$ (Scharlau, Barcelona, Spain), $\mathrm{Fe}\left(\mathrm{NO}_{3}\right)_{3}$ (Carlo Erba, Barcelona, Spain), and $\mathrm{FeCl}_{3}$ (Carlo Erba, Barcelona, Spain). A control experiment without iron was also performed. To study the effect of iron concentration on biosurfactant production, bacterial growth and chemical oxygen demand (COD) removal, $\mathrm{FeSO}_{4}$ was added to the microbial cultures with DCF at concentrations of $0.1,0.2,0.4$ and $0.6 \mathrm{mM}$. The compounds $\mathrm{Fe}\left(\mathrm{NO}_{3}\right)_{3}$ and $\mathrm{FeCl}_{3}$ were added at concentrations of 0.1 and $0.6 \mathrm{mM}$. In all experiments, the flasks were incubated in triplicate for $24 \mathrm{~h}$ at $30^{\circ} \mathrm{C}$ and $100 \mathrm{rpm}$. 


\subsection{Biosurfactant Isolation, Extraction and Partial-Purification}

For the isolation of the BS, a method similar to Suryanti et al. (2013) [22] was followed. In particular, following the completion of each experiment, the cultures were centrifuged for $25 \mathrm{~min}$ at $4500 \mathrm{rpm}$ to precipitate and remove the biomass. The BS recovery process initiated from the cell-free supernatants of DCF containing media where the $\mathrm{pH}$ was adjusted to 2 using $1 \mathrm{M} \mathrm{H}_{2} \mathrm{SO}_{4}$. The samples were incubated at $4{ }^{\circ} \mathrm{C}$ overnight. On the next day, the supernatant was centrifuged for $30 \mathrm{~min}$ at $4500 \mathrm{rpm}$, resulting in the precipitation of the BS, and the supernatant was discarded. A total of $5 \mathrm{~mL}$ of a mixture of chloroform: methanol $(2: 1 \mathrm{v} / \mathrm{v})$ was added to the precipitated BS. The mixture was mixed vigorously, resulting in BS dissolution. The mixture was incubated at $30^{\circ} \mathrm{C}$ for $15 \mathrm{~min}$. Following that, the BS solution was centrifuged for $30 \mathrm{~min}$ at $4500 \mathrm{rpm}$, leading to the precipitation of the partially purified BS. The supernatant was discarded, the precipitate was left to dry, and was kept at $-20^{\circ} \mathrm{C}$.

\subsection{Analytical Methods: Chemical Oxygen Demand (COD)}

Following the completion of each experiment, the cultures were centrifuged for $25 \mathrm{~min}$ at $4500 \mathrm{rpm}$ to precipitate and remove the biomass. A total of $1 \mathrm{~mL}$ of the supernatant was collected and diluted in $4 \mathrm{~mL}$ of distilled $\mathrm{H}_{2} \mathrm{O}$ ( $\times 5$ dilution). The method for the determination of COD was based on instructions by a kit (Supelco, Inc, Sigma-Aldrich, St. Louis, MI, USA) with COD range between 500 to $10,000 \mathrm{mg} / \mathrm{L}$. The sample was diluted to fall within the kit COD range. The method agrees with the DIN ISO 15,705 and is similar to EPA410.4, APHA 5220D, and ASTM D1252-06 B. The kit provides the cell which contains sulfuric solution of potassium dichromate and silver sulfate as catalyst. Kit instructions for sample preparation, incubation and COD quantification were followed. Briefly, $1 \mathrm{~mL}$ of the diluted sample was added to the cell. The cell was vigorously mixed and then heated at $148{ }^{\circ} \mathrm{C}$ in a pre-heated thermoreactor (CR 3200, WTW, Xylem Analytics, Weilheim, Germany) for $120 \mathrm{~min}$. Following complete cooling of the cell down to room temperature, the COD concentration was measured in a photometer (Spectroquant pharo 100, Merck Millipore, Darmstadt, Germany). The control for the COD measurement contained the medium and $1 \%(v / v)$ DCF.

\subsection{Antimicrobial Activity}

\subsubsection{Bacterial Strains Tested}

The antimicrobial activity of the studied biosurfactant was tested against Gramnegative and Gram-positive multi-drug resistant bacteria purchased from Leibniz Institute DSMZ-German Collection of Microorganisms and Cell Cultures GmbH (Germany). All the purchased microorganisms were grown in the relevant culture conditions recommended by the company. Furthermore, the antimicrobial activity was tested against an Escherichia coli strain and Enterococcus faecalis strain, isolated from the municipal wastewater treatment of Limassol (Cyprus). These two strains, in the present study, were called Escherichia coli resistant and Enterococcus faecalis resistant.

The Gram-negative bacteria purchased were: Klebsiella pneumoniae (DSM 681), Pseudomonas aeruginosa (DSM 19880), Escherichia coli (DSM 17076), Acinetobacter baumaniii (DSM 24110). The Gram-positive bacteria were: Enterococcus faecalis (DSM 20409), Streptococcus pneumoniae (DSM 11865), Staphylococcus aureus (DSM 799), Salmonella enterica (DSM 26655).

\subsubsection{Preparation of Biosurfactant Solution}

The BS was dissolved in $5 \%(v / v)$ methanol in distilled $\mathrm{H}_{2} \mathrm{O}$. The $\mathrm{pH}$ of the solution was adjusted to 9 . The concentration of the biosurfactant in the solution was adjusted to either 1 or $10 \mathrm{mg} / \mathrm{mL}$ and serial dilutions in distilled $\mathrm{H}_{2} \mathrm{O}$ were prepared to adjust to lower concentrations of the BS, as needed. In particular, $1 \mathrm{mg} / \mathrm{mL}$ was diluted to 0.25 and $0.5 \mathrm{mg} / \mathrm{mL}$, whereas $10 \mathrm{mg} / \mathrm{mL}$ was diluted to $5 \mathrm{mg} / \mathrm{mL}$ to test the minimum inhibitory concentration of the BS, as described in Section 2.7.4 below. The control solution was $5 \%$ $(v / v)$ methanol in distilled $\mathrm{H}_{2} \mathrm{O}$ with $\mathrm{pH} 9$. 


\subsubsection{Agar Disc Susceptibility Test}

The antimicrobial activity was determined using the standard clear zone inhibition halo method [23]. The susceptibility of the test strains against the BS was tested with the agar disc diffusion test. The method is similar to that used by Das et al. (2008), with a few modifications. For the test, all the bacterial test strains, including the isolated strains, were cultured overnight in sterile trypticase soy broth (TSB) at $37^{\circ} \mathrm{C}$. TSB contains $17 \mathrm{~g}$ tryptone (pancreatic digest of casein), $3 \mathrm{~g}$ soytone (peptic digest of soybean), $2.5 \mathrm{~g}$ glucose (=dextrose), $5 \mathrm{~g}$ sodium chloride, $2.5 \mathrm{~g}$ dipotassium phosphate per litter of $\mathrm{dH}_{2} \mathrm{O}$ at $\mathrm{pH}$ $7.3 \pm 0.2$. The $\mathrm{OD}$ of all broth cultures was adjusted to 0.1 equivalents to an inoculum of $1.5 \times 10^{-8} \mathrm{CFU} \mathrm{ml}{ }^{-1}$ (according to McFarland turbidity standards). Exactly $500 \mu \mathrm{L}$ of each of the diluted in TSB cultures was used to inoculate agar plates by flooding their surface and spreading them uniformly on plates. The excess liquid broth was allowed to air dry for 15 min under the sterile environment of a biosafety laminar flow cabinet (Esco, Barnsley, UK). The agar disc diffusion was performed, following optimization experiments, on sterile TSB agar (Sigma-Aldrich ltd, St. Louis, MI, USA) (K. pneumoniae, P. aeruginosa, E. coli resistant, E. coli, A. baumaniii, S. pneumoniae), sterile TSB with yeast extract agar (Liofilchem, Roseto degli Abruzzi, Italy) (E. faecalis resistant, E. faecalis, S. aureus) and sterile nutrient agar (Scharlau, Barcelona, Spain) (S. enterica) plates. TSB with yeast extract contains $30 \mathrm{~g}$ TSB, 3 g yeast extract and $15 \mathrm{~g}$ agar per liter of $\mathrm{dH}_{2} \mathrm{O}$. Nutrient agar contains $1 \mathrm{~g}$ meat extract, $2 \mathrm{~g}$ yeast extract, $5 \mathrm{~g}$ peptone, $5 \mathrm{~g}$ sodium chloride, $15 \mathrm{~g}$ agar per litter of $\mathrm{dH}_{2} \mathrm{O}$. Sterile Whatman filter paper (No. 1) discs of $6 \mathrm{~mm}$ diameter, impregnated with $15 \mu \mathrm{L}$ of the different stock solutions of the BS, were kept aseptically on the surface of these pre-inoculated plates. A disc soaked in the control solution (as described in Section 2.7.2 above) was kept as a negative control. The plates were incubated at $37^{\circ} \mathrm{C}$ for $48 \mathrm{~h}$ and, after growth, the microbial growth inhibition zones around the discs were measured. All tests were performed in four replicates and the inhibition zone diameter values $(\mathrm{mm})$ were expressed as the mean value \pm standard deviation (SD).

\subsubsection{Minimum Inhibitory Concentration (MIC) Agar Susceptibility Test}

The agar disc diffusion test was carried out to determine the minimum inhibitory concentration (MIC) of the BS against the different tested microorganisms. The plates inoculated with the tested microorganisms were prepared as presented to Section 2.7.3. Sterile Whatman (No. 1) filter paper discs were impregnated with $15 \mu \mathrm{L}$ of different dilutions of the solution of the partially purified BS. Those discs were then kept aseptically on the surface of the pre-inoculated plates. The plates were incubated at $37^{\circ} \mathrm{C}$ for $48 \mathrm{~h}$. The minimum concentration of the BS, which showed a clear zone of inhibition around the applied disc, was considered as their MIC against that particular microorganism. All tests were performed in four replicates and the inhibition zone diameter values ( $\mathrm{mm}$ ) were expressed as the mean value \pm standard deviation (SD). A disc soaked in the control solution (as described in Section 2.7.2 above) was kept as a negative control.

\subsection{Emulsification Index (E24)}

The emulsification index (E24) was determined by adding $2 \mathrm{~mL}$ of DCF to the same amount of two different aqueous solutions $(5 \%(w / v)$ and $1 \%(w / v))$ of biosurfactant extracted as above. The DCF-biosurfactant solution was vortexed at maximum speed for $2 \mathrm{~min}$ and left to stand for $24 \mathrm{~h}$. After that time period, the E24 was calculated as the percentage of height of emulsified layer $(\mathrm{mm})$ divided by the total height of the liquid column (mm) [24] (Equation (1)). The emulsification percentage was determined based in triplicates.

$$
\text { E24 }=(\text { Height of emulsion layer } / \text { Total height of solution }) \times 100
$$




\subsection{Surface Tension}

The BS surface tension was estimated based on the method of capillary rise [25-27]. The surface tension was determined based on the P. citronellolis isolated strain growth in M9 minimal media and $\mathrm{MgSO}_{4}$ at $30{ }^{\circ} \mathrm{C}$ and $\mathrm{pH}$ 7. The biomass was removed and the BS was extracted as described in Section 2.5. Before being stored at $-20^{\circ} \mathrm{C}$, the BS was dissolved in water. The density of the BS was $1.78 \mathrm{~g} / \mathrm{mL}$. Surface tension was determined using Equation (2), where $d$ is the liquid density, $h$ the height of the capillary, $r$ the capillary radius, $\gamma$ the surface tension and $\theta$ the contact angle. Since the liquid completely wet the capillary walls, the contact angle $\theta$ was considered $0^{\circ}$, and $\cos \theta$ was equal to 1 .

$$
\gamma=(\operatorname{rhdg}) /(2 \cos \theta)
$$

\subsection{Fourier Transform Infrared Spectroscopy (FTIR)}

The FTIR measurements were performed with a Bruker (Mannheim, Germany) Vertex 70 FTIR-spectrometer. The spectra were recorded in the attenuated total reflectance (ATR) mode by using a Pike Miracle ATR accessory configured with a single reflection ZnSe crystal. The biosurfactant was placed in the ZnSe crystal in powder form and a highpressure clamp was used to improve contact between the sample and the ATR crystal. A background spectrum was recorded with a clean crystal before each measurement. ATR-FTIR spectra were recorded between 4000 and $600 \mathrm{~cm}^{-1}$ at a resolution of $4 \mathrm{~cm}^{-1}$.

\subsection{Thermal Gravimetric Analysis (TGA) and Differential Thermal Analysis (DTA)}

Simultaneous differential thermal analysis (DTA) and thermogravimetry (TG) on a representative sample of mass $13.61 \mathrm{mg}$ of the extracted BS were undertaken using a Shimadzu (Kyoto, Japan) DTG-60H analyzer. These analyses were carried out from room temperature (ca. $25^{\circ} \mathrm{C}$ ) to $800{ }^{\circ} \mathrm{C}$, at a heating rate of $5{ }^{\circ} \mathrm{C} / \mathrm{min}$, in a flowing dry nitrogen atmosphere $(20 \mathrm{~mL} / \mathrm{min})$.

\subsection{X-ray Diffraction (XRD) Analysis}

The X-ray diffraction (XRD) analysis of the extracted BS (mass = $13.61 \mathrm{mg}$ ) was also performed using a Bruker (Mannheim, Germany) D8 Advance system with $\mathrm{Cu} K \alpha$ radiation $(\lambda=0.1541 \mathrm{~nm})$ at $40 \mathrm{kV}$ and $40 \mathrm{~mA}$. The analysis was carried out with continual rotation of the sample and a step of $10^{\circ} / \mathrm{min}$ within the $10-80^{\circ} 2 \theta$ angle range. The International Centre for Diffraction Data (ICDD) Powder Diffraction File (PDF) 4 database was used for the qualitative identification of the amino acids.

\subsection{Statistical Analysis}

For the antimicrobial activity test four technical replicates of each assay (i.e., agar disc susceptibility method and MIC) were performed on the same day with the same solution of the BS which was extracted from each experiment. Each experiment was performed in biological triplicates. The results are stated as mean $\pm \mathrm{SD}$.

\section{Results and Discussion}

3.1. Identification of the Microorganism, Production of BS and Determination of Surface Tension and Emulsification Index (E24)

DNA sequencing of three different single colonies derived from the isolation experiment showed that each colony was derived from the same microorganism. It is likely that the presence of biocides in the DCF prevented the isolation of more than one microorganism. According to BLAST results, following genome annotation of the draft genome sequence, the top ten (10) hits recognize that the microorganism is Pseudomonas citronellolis. The current isolated strain showed a 97-99\% homology with P. citronellolis P3B5 or SJTE-3 (Table S1, Supplementary Material). Hence, current strain holds the potential to be a novel strain of P. citronellolis which, herein, was named P. citronellolis 620C. The genomes of both P3B5 and SJTE-3 strains were completely sequenced and both strains have been identi- 
fied as hydrocarbon-degrading [28,29]. Furthermore, P3B5 has also been characterized as surfactant-producing using diesel as a substrate [30]. Nevertheless, analysis of the microorganism genome is beyond the scope of the present study.

BS formation is usually demonstrated from the late exponential phase until the end of the stationary phase [31], while the release of cell-bound BS in the medium leads to a decrease in surface tension, even after the stationary phase [32]. In the current study, it was observed that microbial growth, with $1 \%$ DCF as a substrate, was reduced at $26 \mathrm{~h}$ of culture and the BS was extracted at that time point. The surface tension of water and BS solution were $72.1 \mathrm{mN} / \mathrm{m}$ and $32.8 \mathrm{mN} / \mathrm{m}$, respectively. Therefore, BS efficiently reduced the surface tension of water. The surface tension of the BS solution was similar to other studies in the literature, whereby BS was produced by Pseudomonas species. For instance, Singh et al. 2016 [31] reported a reduction in surface tension of a BS formed by P. otitidis P4 from 71.18 to $33.4 \mathrm{mN} / \mathrm{m}$. Recently, a mixture of biosurfactants formed by P. syringae pv. tabaci reduced the surface tension of water down to $36.89 \mathrm{mN} / \mathrm{m}$ [33].

The formation of BS increases the bioavailability and biodegradation of hydrocarbons [34]. An indication of the increased bioavailability is the emulsification index (E24). The E24 using two solutions of BS with $1 \%(w / v)$ and $5 \%(w / v)$ BS concentration was $24.8 \%$ and $44.6 \%$, respectively. The E24 results did not show high emulsification of the BS, despite the different concentration of BS used. This indicates that the current BS could be a low molecular weight molecule. Low molecular weight biosurfactants are the glycolipids or lipopeptides [35]. For instance, E24 of the glycolipid named rhamnolipid formed by P. fluorescens was up to $10 \%$ and $49 \%$ upon growth on hexadecane and olive oil, respectively [36]. Furthermore, several lipopeptides showed a E24 between 20-31\% upon Pseudomonas spp growth on hexadecane biodegradation [37]. In another study, among several P. citronellolis isolates from hydrocarbon contaminated soil, the E24 ranged between $43.75-70.45 \%$ [38], showing low and high emulsification capability. Finally, upon E24 testing of a BS produced by P. citronellolis $222 \mathrm{~A}$, emulsification was not detected, indicating that the molecular weight of the BS produced by that strain was not high [39].

\subsection{Microbial Growth and the Effect of Different Iron Forms}

In this study, the effect of different iron forms, at different concentration levels, on the microbial growth of $P$. citronellolis isolate $620 \mathrm{C}$ was evaluated. In particular, $\mathrm{FeSO}_{4}, \mathrm{FeCl}_{3}$ and $\mathrm{Fe}\left(\mathrm{NO}_{3}\right)_{3}$ forms were studied based on the results reported by Santos et al. (2008) [40]. In that study, the effect of different iron forms on anthracene and other hydrocarbons degradation, and BS production was demonstrated using P. citronellolis and P. aeruginosa isolates. In the current study, to demonstrate the level of toxicity of iron forms on $P$. citronellolis $620 \mathrm{C}, \mathrm{FeSO}_{4}$ supplementation was studied at concentration levels of $0.1,0.2,0.4$ and $0.6 \mathrm{mM}$ (Figure 1A). Santos et al. (2008) reported that the addition of iron forms at a concentration $\geq 0.5 \mathrm{mM}$ was inhibitory for microbial growth. The results were compared to microbial growth without the addition of iron forms. It was observed that the addition of $0.1 \mathrm{mM}$ of $\mathrm{FeSO}_{4}$ greatly enhanced microbial growth, similarly to Santos et al. 2008 [40] who chose that concentration level for further studies. Furthermore, unlike Santos et al. 2008 [40], the addition of higher than $0.1 \mathrm{mM}$ concentrations of $\mathrm{FeSO}_{4}$ did not affect the growth of $P$. citronellolis isolate 620C.

Following that, the effect of adding $\mathrm{FeCl}_{3}$ and $\mathrm{Fe}\left(\mathrm{NO}_{3}\right)_{3}$ forms was studied. These iron forms were supplemented in the microbial culture at the lowest (i.e., $0.1 \mathrm{mM}$ ) and highest (i.e., $0.6 \mathrm{mM}$ ) concentration level of $\mathrm{FeSO}_{4}$. This was performed to check microbial growth at the concentration level of Fe compounds which promotes microbial growth, according to the previous experiment (i.e., $0.1 \mathrm{mM}$ of $\mathrm{FeSO}_{4}$ ) and one above the limit of toxicity, according to Santos et al. (2008), which is $0.6 \mathrm{mM}$. Microbial growth kinetics were evaluated at regular time points (Figure 1B). The results were compared to microbial growth without the addition of iron forms. It was observed that $0.1 \mathrm{mM}$ of both iron forms significantly enhanced microbial growth, while the addition of $0.6 \mathrm{mM}$ resulted in the inhibition of $P$. citronellolis $620 \mathrm{C}$ growth. The latter can be attributed to the toxicity that 
may have been caused to the microorganism's metabolism. These results are in accordance to Santos et al. 2008 [40]. Furthermore, the addition of $0.1 \mathrm{mM}$ of the three different iron forms was compared to each other and to the microbial growth without the addition of any iron form (Figure 1C). Among the three iron forms, the addition of $\mathrm{FeCl}_{3}$ resulted in the highest microbial growth. Overall, when iron was supplemented in the microbial culture at the lowest concentration, microbial growth was significantly increased.
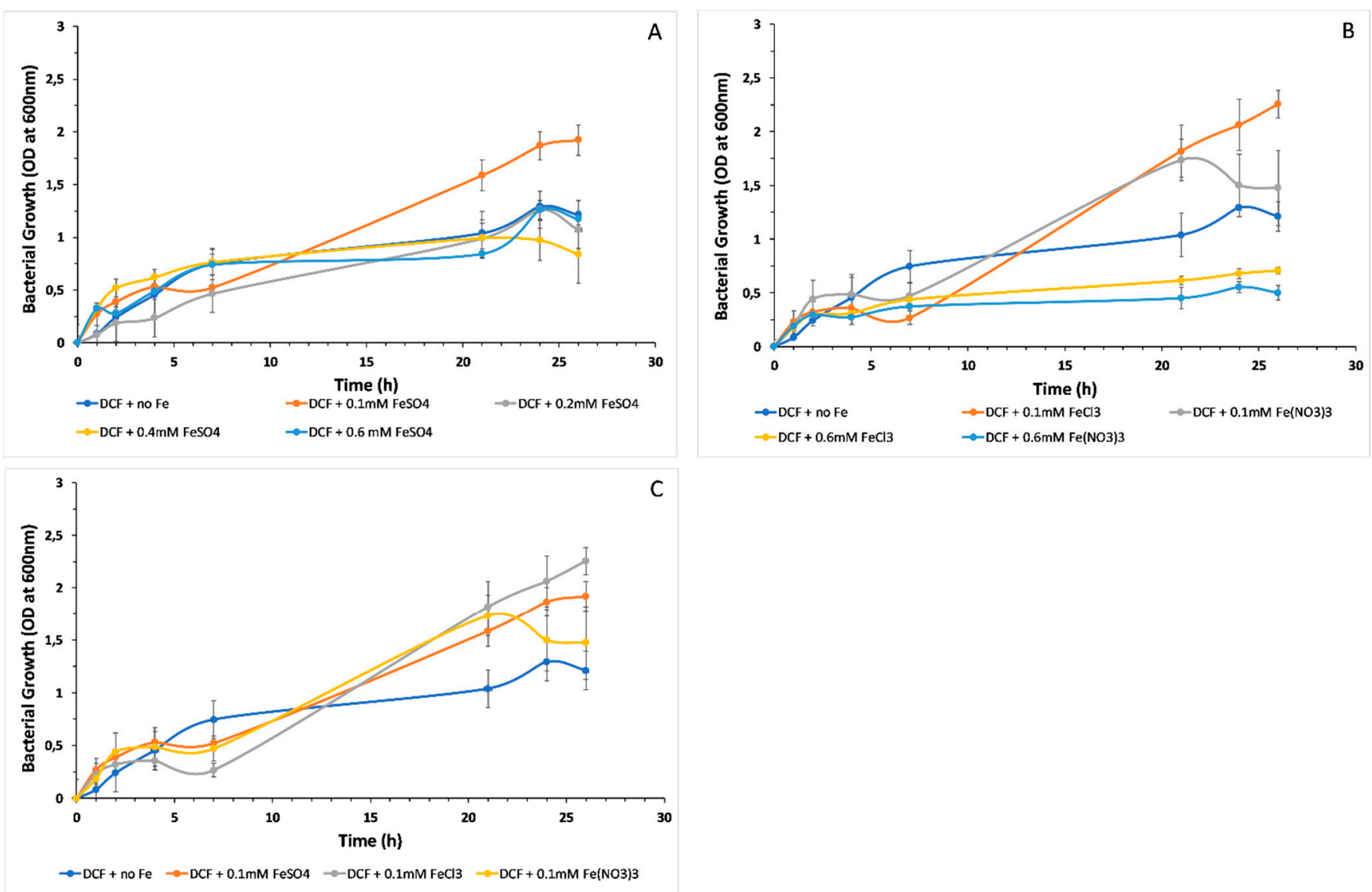

Figure 1. Microbial net growth of P. citronellolis $620 \mathrm{C}$ with $1 \%(v / v)$ drill cutting fluid (DCF) as substrate: (A) with and without the supplementation of different concentration levels of $\mathrm{FeSO}_{4},(\mathbf{B})$ with and without the addition of high and low concentration level of $\mathrm{FeCl}_{3}$ and $\mathrm{Fe}\left(\mathrm{NO}_{3}\right)_{3},(\mathbf{C})$ comparison when different $0.1 \mathrm{mM}$ iron forms are supplemented.

Several necessary functions of microbial metabolism are performed due to iron participation, such as the protection of the cells against superoxide radicals, whilst iron is also a key component of cytochromes and contributes to the Krebs cycle [41]. However, the limit between deficiency and toxicity is narrow. For instance, iron can interact with reactive oxygen species, such as hydrogen peroxide and superoxide, forming greatly damaging and reactive hydroxyl radicals. Furthermore, bacteria are highly sensitive in the presence of redox agents upon growth under iron-supplemented conditions [42]. Therefore, low amounts of iron are required.

The presence of oxygen leads to insolubility and low reactivity of $\mathrm{Fe}$, and thus, low bioavailability and higher toxicity [40]. For instance, the predominant form of Fe, ferric iron, which exists in rhizosphere, is highly insoluble. Therefore, it is possible that appropriate concentrations of soluble iron forms can enhance the microbial growth, resulting in increased hydrocarbon biodegradation and, thus, higher microbial growth, as observed in the rhizosphere $[43,44]$.

Consequently, in the present study, the effect of iron forms on microbial growth was more evident when more soluble iron forms were used. Specifically, microbial growth 
was further increased when $\mathrm{FeCl}_{3}$ and $\mathrm{Fe}\left(\mathrm{NO}_{3}\right)_{3}$ were added to the microbial cultures, compared to $\mathrm{FeSO}_{4}$ addition. The addition of more soluble forms of iron increases iron availability to the microorganism. $\mathrm{FeSO}_{4}$ is relatively insoluble in water, therefore, an increase in the concentration of $\mathrm{FeSO}_{4}$ leads to an increase in insolubility. Thus, the insignificant effect of $>0.1 \mathrm{mM}$ concentration of $\mathrm{FeSO}_{4}$ in the microbial culture may also be attributed to insolubility, which inevitably leads to a lower interaction of Fe with the microbial culture. Another cause of the lower effect of $\mathrm{FeSO}_{4}$ to the microbial growth could be that this compound may also cause microbial culture acidification [40].

\subsection{Biosurfactant Production and the Effect of Different Iron Forms}

In the current study, BS production was evaluated upon supplementation of the microbial culture with $\mathrm{FeSO}_{4}$ at the concentration level of $0.1,0.2,0.4$ and $0.6 \mathrm{mM}$ (Figure 2A). Santos et al. (2008) reported that the addition of iron forms at concentrations $\geq 0.5 \mathrm{mM}$ was inhibitory for microbial growth and, thus, BS production. The results were compared to BS production without the addition of iron forms. It was observed that the addition of $0.1 \mathrm{mM}$ of $\mathrm{FeSO}_{4}$ greatly enhanced BS production, in line with the results of Santos et al. 2008 [40]. Specifically, the BS yield was increased by $95 \%$, as shown in Figure 2A. Furthermore, addition of higher concentrations of $\mathrm{FeSO}_{4}$ led to lower levels of $\mathrm{BS}$ production than the control specimen, despite the fact that those concentration levels did not negatively affect the growth of P. citronellolis 620C. These results are consistent with those of Santos et al. 2008 [40], suggesting a strong correlation and dependence of iron and BS formation up to a limit where iron is not beneficial for BS formation. Following that, the addition of $\mathrm{FeCl}_{3}$ and $\mathrm{Fe}\left(\mathrm{NO}_{3}\right)_{3}$ were supplemented in the microbial culture at the lowest (i.e., $0.1 \mathrm{mM}$ ) and highest (i.e., $0.6 \mathrm{mM}$ ) concentration levels. It was observed that $0.1 \mathrm{mM}$ of both iron forms greatly increased BS production. In particular, the addition of $0.1 \mathrm{mM}$ of $\mathrm{FeCl}_{3}$ and $\mathrm{Fe}\left(\mathrm{NO}_{3}\right)_{3}$ resulted in a $112 \%$ and $90 \%$ increase, respectively, whereas the addition of $0.6 \mathrm{mM}$ resulted in BS production that was lower than the control specimen (Figure 2B). The results were similar to the microbial growth results and they could be attributed to the toxicity that may have been caused to the microorganism's metabolism, leading to low microbial growth and, thus, limited BS formation. These results are also in accordance to Santos et al. 2008 [40]. BS production was compared upon addition of $0.1 \mathrm{mM}$ of the three different iron forms (Figure 2C). Among the three iron forms, the addition of $\mathrm{FeCl}_{3}$ resulted in the highest BS formation, which corresponds to the highest microbial growth. Overall, similarly to microbial growth, when iron was supplemented in the microbial culture at the lowest concentration, BS production was significantly increased. The addition of iron forms to the growth medium of Bacillus subtilis [45] and P. citronellolis strains [40] resulted in overproduction of the relevant BSs. Makkar and Cameotra (2002) also reported that metal ion addition greatly enhanced BS production [46]. Several other studies have also evaluated the positive effect of Fe nanoparticles on BS production [2,18].

Furthermore, in the present study, $\mathrm{FeCl}_{3}$ addition resulted in the highest $\mathrm{BS}$ yield, over-doubling the production. This is in line with Dinkla et al. (2001) [43], who reported the positive effect of $\mathrm{FeCl}_{3}$ on $\mathrm{BS}$ formation upon toluene biodegradation. In another study of the production of BS by marine Nocardiopsis lucentensis MSA04 in solid-state cultivation, $\mathrm{FeCl}_{3}$ was found to be the most suitable metal precursor [47]. Therefore, the addition of more soluble forms of iron at adequate concentrations could be a key strategy for the optimization of BS production. 

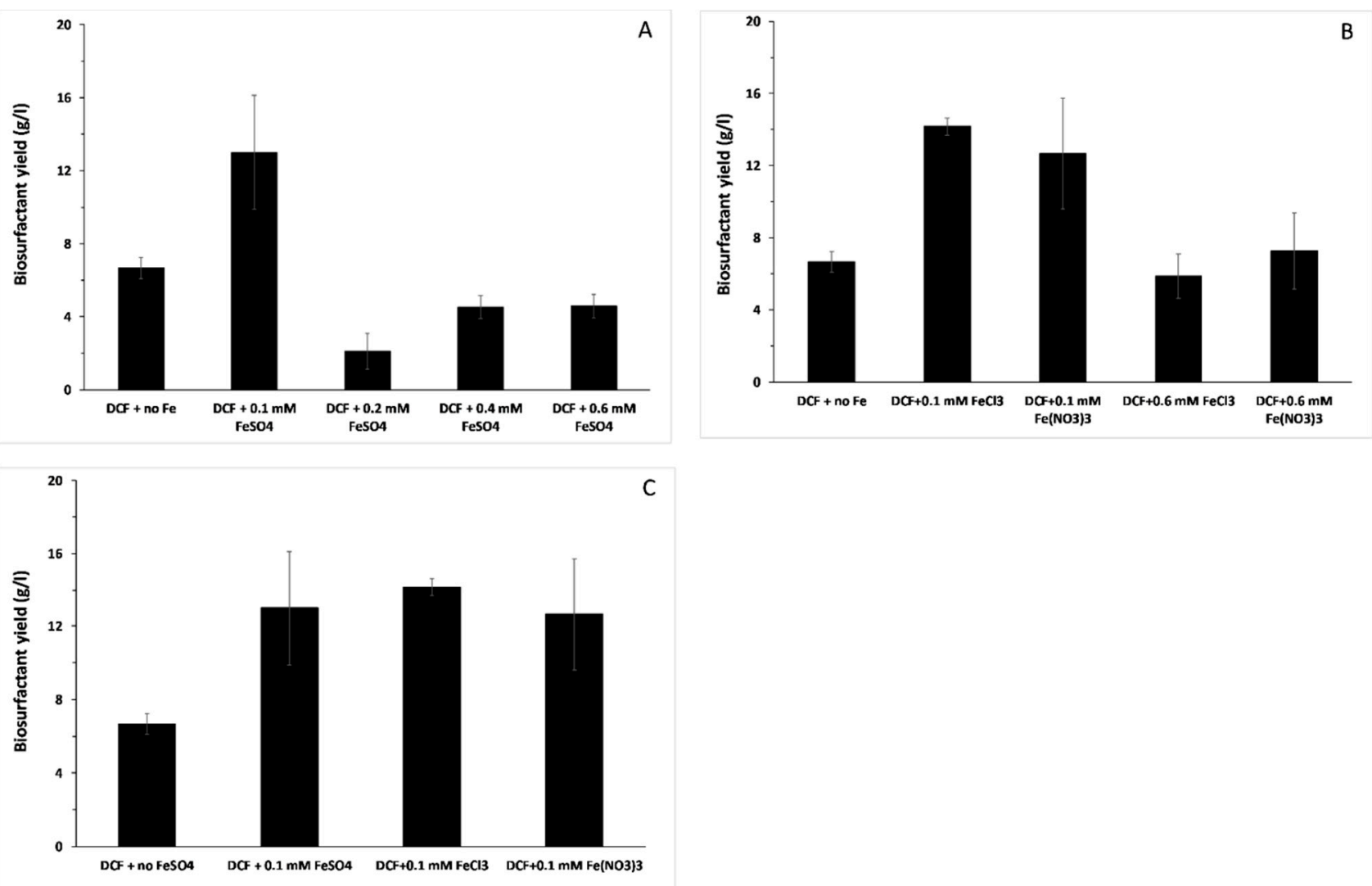

Figure 2. Biosurfactant production by $P$. citronellolis $620 \mathrm{C}$ with $1 \%(v / v)$ DCF as substrate, based on the product yield of the biosurfactant (BS) over drilling waste consumption: (A) with and without supplementation of different concentration levels of $\mathrm{FeSO}_{4}$, (B) with and without the addition of high and low concentration levels of $\mathrm{FeCl}_{3}$ and $\mathrm{Fe}\left(\mathrm{NO}_{3}\right)_{3},(\mathbf{C})$ comparison when different $0.1 \mathrm{mM}$ iron forms were supplemented.

\subsection{COD Removal and the Effect of Different Iron Forms}

BSs enhance the bioremediation of oil waste [14]. Therefore, COD was studied to observe the effect of enhanced biodegradation due to BS production. The effect of the addition of the different iron forms was also evaluated through COD measurement. The experimental conditions were similar as those mentioned above (Section 3.2). The $\mathrm{FeSO}_{4}$ effect on \% COD removal of DCF was studied upon the addition of $0.1,0.2,0.4$ and $0.6 \mathrm{mM}$ (Figure 3A), whereby a slight increase in the \% COD removal was observed, compared to the control experiment (i.e., without iron addition). The results followed the microbial growth results, suggesting that $\mathrm{FeSO}_{4}$ addition does not greatly affect the metabolic pathways related to hydrocarbons and biomass formation activities. Following that, the effect of addition of 0.1 and $0.6 \mathrm{mM} \mathrm{FeCl}_{3}$ and $\mathrm{Fe}\left(\mathrm{NO}_{3}\right)_{3}$ was studied (Figure $3 \mathrm{~B}$ ), whereby at $0.1 \mathrm{mM}$, both forms increased the \% COD removal, with the effect of $\mathrm{FeCl}_{3}$ being more pronounced, in agreement with the previous results of the present study. Additionally, at $0.1 \mathrm{mM}$ addition, among the three iron forms, $\mathrm{FeCl}_{3}$, similarly to the microbial growth and BS production, further enhanced the \% COD removal, demonstrating its positive effect in the bioprocess (Figure 3C).

It was noticed that, although the different iron forms resulted in increased \% COD removal, compared to the COD removal without the supplementation of iron forms, the removal was not as high as that of the COD removal reported in other studies (e.g., Santos et al., 2008), whereby pure hydrocarbon forms were used, such as anthracene. It is suggested that the higher COD removal observed in the microbial cultures supplemented with iron was due to the higher availability of iron for induction, expression and activity of the enzymes catalyzing hydrocarbon biodegradation, as iron is a key element of oxygenases [48]. Furthermore, at low iron concentration, the direct dependence of the BS on the 
presence of iron, which resulted in BS over-production, probably increased hydrocarbon bioavailability to degradation, thus, leading to an increase in the \% COD removal.

DCF is a highly toxic waste stream which, unless safely disposed, can lead to an adverse impact on human health and the environment due to its hazardous components and additives [49]. DCF biodegradation is an alternative eco-friendly approach for disposal management which is enhanced by BSs produced during the microbial bioprocess [50]. Therefore, the potential of $P$. citronellolis $620 \mathrm{C}$ to be used in a scaled-up bioprocess was examined. The enhancement of DCF biodegradation through the use of the BS-producing P. citronellolis $620 \mathrm{C}$ was also evaluated at higher than $1 \%(v / v)$ DCF concentrations (i.e., $5 \%$ and $10 \%$ ) through monitoring of microbial growth kinetics and \% COD removal. Despite the toxicity of the DCF (initial COD: $41.000 \mathrm{mg} / \mathrm{L}$ ), the \% COD removal was promising (i.e., $42 \%$ and $27.5 \%$, respectively) (Supplementary Material Figure S1).
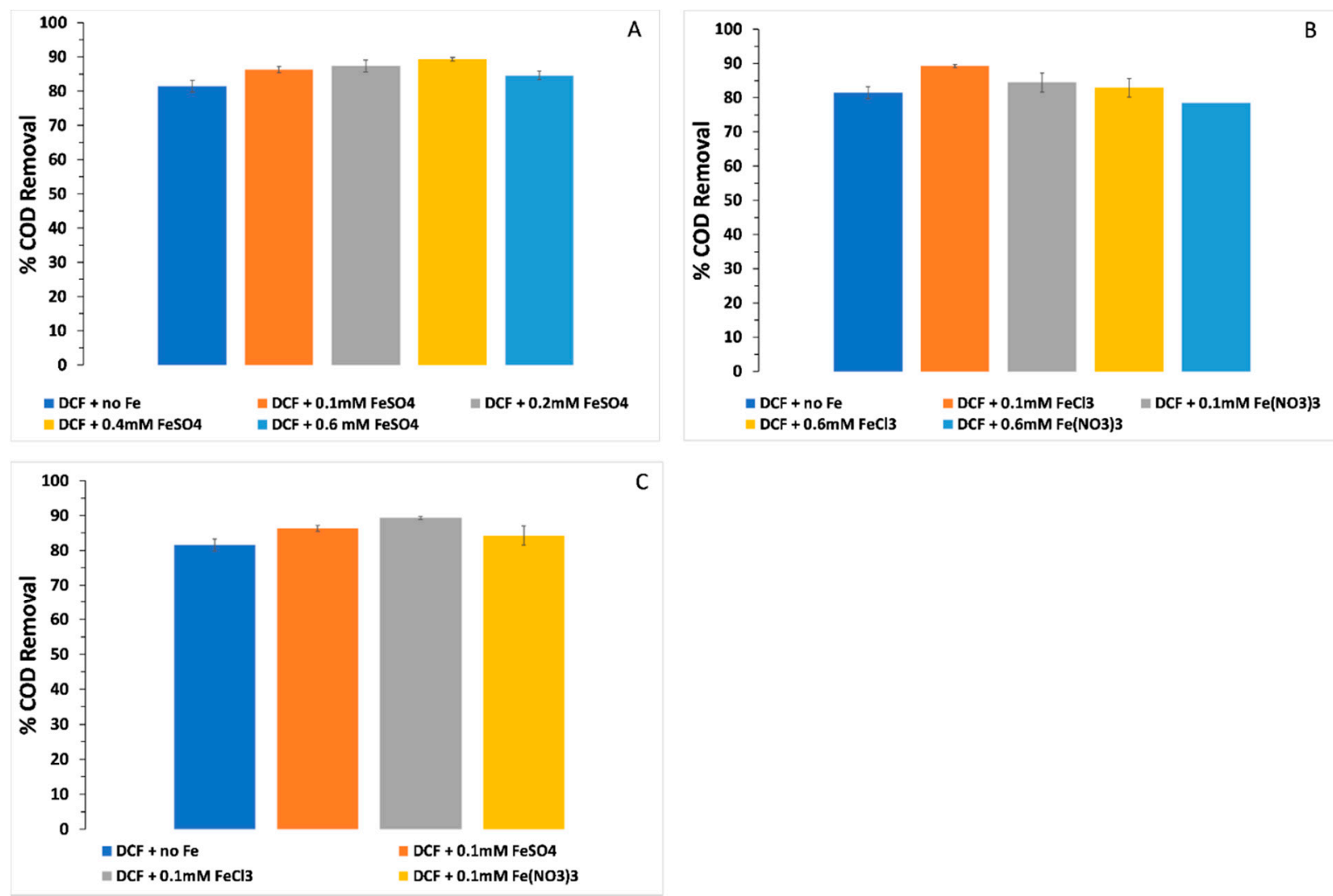

Figure 3. \% chemical oxygen demand (COD) removal of DCF in P. citronellolis 620C culture with $1 \%(v / v)$ DCF as substrate: (A) with and without the supplementation of different concentration levels of $\mathrm{FeSO}_{4}$, (B) with and without the addition of high and low concentration levels of $\mathrm{FeCl}_{3}$ and $\mathrm{Fe}\left(\mathrm{NO}_{3}\right)_{3},(\mathrm{C})$ comparison when different $0.1 \mathrm{mM}$ iron forms were supplemented.

\subsection{Biosurfactant Characterization}

\subsubsection{FTIR}

FTIR spectroscopy is a valuable tool in the identification of the chemical structure of compounds, as FTIR spectra comprise bands that are characteristic for specific chemical bonds. In this work, the ATR-FTIR approach was employed, as it offers the advantage of working with solid or liquid samples with minimal sample preparation prior to spectral measurements. The ATR-FTIR spectra of the powder form of the BS are shown in Figure 4, with traces $\mathrm{a}$ and $\mathrm{b}$ corresponding to the spectra of the BS produced by the P. citronellolis $620 \mathrm{C}$ culture in the absence and presence of $\mathrm{FeSO}_{4}$, respectively. The vibrations detected in the ATR-FTIR spectra are characteristic of a peptide structure [51]. More specifically, the bands at 3275 and $3075 \mathrm{~cm}^{-1}$ were assigned to the amide A and amide B vibrations 
(N-H stretch) of the peptide, while contributions from O-H bonds in the $3000-3500 \mathrm{~cm}^{-1}$ region cannot be excluded. The peptide backbone, additionally, gave rise to the amide I vibrations ( $\mathrm{C}=\mathrm{O}$ stretch) observed at 1650 and $1625 \mathrm{~cm}^{-1}$, and to the amide II vibration (outof-phase combination of the $\mathrm{NH}$ in plane bend and the $\mathrm{CN}$ stretching vibration) identified at $1530 \mathrm{~cm}^{-1}$ [51]. Furthermore, peaks originating from the $\mathrm{C}-\mathrm{H}$ stretch of $\mathrm{CH}_{3}$ and $\mathrm{CH}_{2}$ groups were detected at 2960, 2930 and $2870 \mathrm{~cm}^{-1}$, demonstrating the presence of alkyl groups [51,52]. To identify additional functional groups in the BS, the $1300-1000 \mathrm{~cm}^{-1}$ region was examined. In this region, bands could be observed at 1225, 1110 and $1050 \mathrm{~cm}^{-1}$. These vibrations were attributed primarily to $\mathrm{C}-\mathrm{C}$ and $\mathrm{C}-\mathrm{O}(\mathrm{H})$ bonds and in conjunction with the contribution of $\mathrm{O}-\mathrm{H}$ bonds in the $\sim 3370 \mathrm{~cm}^{-1}$ region, they provide an indication of the presence of carbohydrate moieties in the peptide [52,53]. Finally, it should be noted that a shoulder was observed in the amide I band at $1720 \mathrm{~cm}^{-1}$. This band could have originated from the $\mathrm{C}=\mathrm{O}$ stretch of Glu or Asp carboxylic acid side chains or from lipid ester group; therefore, a lipopeptide structure is also possible [51,54]. Overall, from the analysis of the ATR-FTIR spectra of the BS described herein and considering the similarity of these spectra to the FTIR spectra of biosurfactants produced by lactic acid [52] and marine [55] bacteria, a glycopeptide or lipopeptide structure is proposed. Furthermore, the FTIR spectra of the BS produced in the absence and presence of $\mathrm{FeSO}_{4}$ were similar, suggesting that Supplementation of the microbial culture with $\mathrm{FeSO}_{4}$ did not affect the structure of the BS.

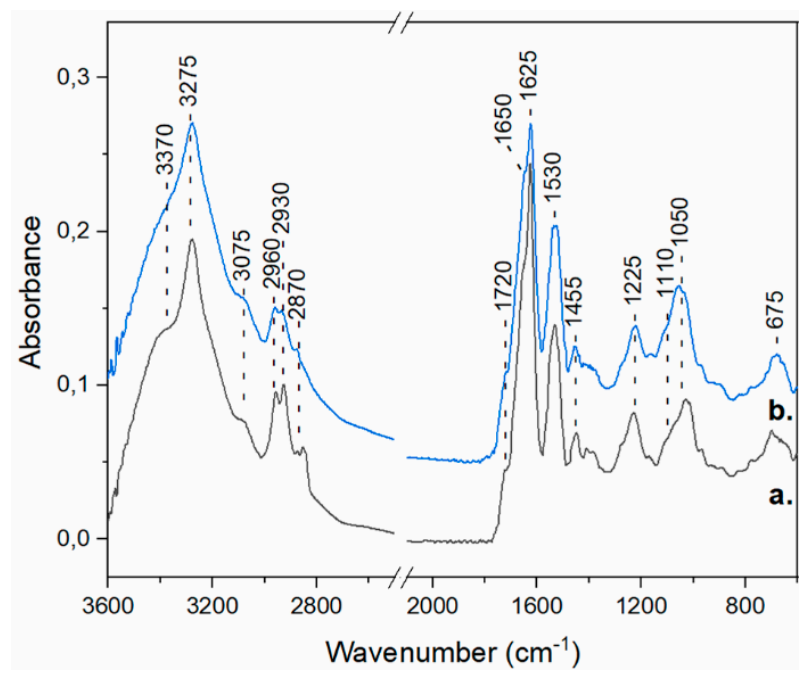

Figure 4. FT-IR analysis of the novel BS extracted and partially purified from $P$. citronellolis isolate $620 \mathrm{C}$ culture with $1 \%$ DCF as substrate: (a) without and (b) with the supplementation of $\mathrm{FeSO}_{4}$.

\subsubsection{TGA, DTA and XRD}

TGA/DTA, and XRD analyses were performed for the partially purified BS extracted by the microbial culture, where $1 \%$ DCF was used as the substrate. The thermal stability of BSs is a key property that is relevant to the applicability of these molecules in industrial and commercial processes [56]. In the first step of TGA (Figure 5A), during the temperature range $27-100{ }^{\circ} \mathrm{C}$, the loss of $\mathrm{BS}$ weight due to the loss of water and solvent molecules was estimated at $9.73 \%$. Thermal degradation takes place upon mass loss of at least $5 \%$ [57]. In the current analysis, following the initial weight loss, $5 \%$ loss of BS weight was observed at 196. $4{ }^{\circ} \mathrm{C}$. This step was followed by a rapid weight loss of $31.22 \%$ until $338.1^{\circ} \mathrm{C}$, which could be attributed to the degradation of thermolabile content, such as carbohydrates and peptides in the BS. The thermal decomposition at $338.1{ }^{\circ} \mathrm{C}$ was confirmed by the exothermic peak of the DTA analysis. These results are similar to those reported by Weiss et al. 2018 [58], where thermal decomposition of several amino acids (i.e., asparagine, glycine, glutamic acid, cysteine, aspartic acid, histidine, arginine and glutamine) was studied, demonstrating decomposition between $200-300{ }^{\circ} \mathrm{C}$. The non-thermolabile content 
was gradually degraded, resulting in BS weight loss of $27.91 \%$ over the temperature range of 338.1-546. ${ }^{\circ} \mathrm{C}$. This could be attributed to fatty acids, which are commonly decomposed over a temperature of $300{ }^{\circ} \mathrm{C}$ [59]. At $546.9^{\circ} \mathrm{C}$, another exothermic peak on the DTA graph was noticed, further confirming the thermal decomposition. As determined from the TGA and DTA graphs, the degradation temperature of BS was found to be $546.9^{\circ} \mathrm{C}$, while complete weight loss took place after $800{ }^{\circ} \mathrm{C}$. Therefore, the BS formed by P. citronellolis isolate $620 \mathrm{C}$ was determined to be thermostable. A similar TGA graph of a lipoprotein BS, produced by Bacillus subtilis, has been established [60].
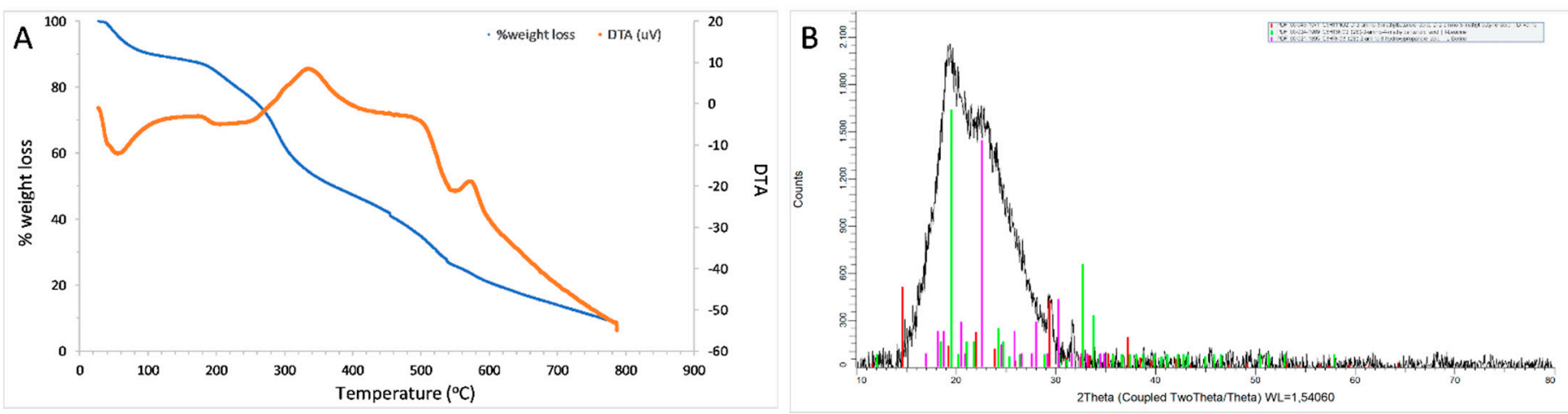

Figure 5. (A) Thermal gravimetric analysis (TGA) and differential thermal analysis (DTA) curves, and (B) XRD analysis of the novel BS extracted and partially purified by P. citronellolis isolate $620 \mathrm{C}$ culture with $1 \%$ DCF as substrate.

The powder XRD pattern (Figure 5B) indicated a highly (57.2\%) amorphous BS with crystallinity index $\left(\mathrm{CI}_{\mathrm{xrd}}\right)$ equal to 0.428 . XRD was used to qualitatively assess the amino acids in the BS. Peptides are usually detected between $20-30^{\circ} 2 \theta$ [61]. As confirmed by the FTIR analysis, the structure of the BS formed by the P. citronellolis $620 \mathrm{C}$ contains amino acids, the building blocks of peptides.

\subsection{Antimicrobial Activity of the Biosurfactant}

The antimicrobial activity was studied using the solution of the partially purified BS, extracted by the P. citronellolis $620 \mathrm{C}$ culture with $1 \%(v / v)$ DCF. The BS showed antimicrobial activity against all the multi-drug resistant Gram-positive and negative microorganisms tested (Table 1).

Firstly, the antimicrobial activity of the BS was tested at a concentration level of $1 \mathrm{mg} / \mathrm{mL}$ (Table 1). This concentration level is commonly used in the agar susceptibility method $[62,63]$. This BS concentration inhibited the growth of the Gram-negative bacteria K. pneumoniae, P. aeruginosa, E. coli resistant and E. coli. In contrast, this level of BS concentration did not inhibit the growth of the Gram-negative A. baumaniii and all the Gram-positive bacteria (i.e., E. faecalis resistant, E. faecalis, S. pneumoniae, S. aureus, S. enterica). These pathogens were inhibited at $10 \mathrm{mg} / \mathrm{mL}$ BS concentration (Table 1). These results indicate that some bacterial pathogens can be more resistant to antimicrobial agents compared to others. Commonly, the inhibition of BS on growth of bacterial pathogens is studied in a broad concentration range from few $\mu \mathrm{g}$ (e.g., $4.9 \mu \mathrm{g}$ ) [64] to $100 \mathrm{mg} / \mathrm{mL}$ [65]. Most probably, this is dependent on the chemical compartments which are contained in a BS, resulting in the antimicrobial activity, purification of the BS tested and the method used which can either be the agar susceptibility method or the micro-broth dilution technique. BSs, such as rhamnolipids at a concentration level of $1.12 \mathrm{mg} / \mathrm{mL}$, caused an inhibition zone similar to that in the present study, against several Gram-negative and -positive bacterial pathogens [63]. The rhamnolipids were isolated and partially purified using a method similar to that of the present study. 
Table 1. In Vitro antimicrobial activity of the partially purified biosurfactant against multidrugresistant pathogenic bacterial strains, using the agar susceptibility method.

\begin{tabular}{ccc}
\hline & Biosurfactant $\mathbf{( m g / m L )}$ & $\begin{array}{c}\text { Antimicrobial Zone } \\
\text { Diameter }(\mathbf{m m})\end{array}$ \\
\hline Klebsiella pneumoniae & 1 & $9.0 \pm 0.7$ \\
Pseudomonas aeruginosa & 1 & $8.8 \pm 0.8$ \\
Escherichia coli resistant & 1 & $10.5 \pm 1.5$ \\
Escherichia coli & 1 & $8.8 \pm 0.4$ \\
Enterococcus faecalis resistant & 10 & $9.3 \pm 2.2$ \\
Enterococcus faecalis & 10 & $8.3 \pm 1.9$ \\
Acinetobacter baumaniii & 10 & $7.3 \pm 5.3$ \\
Streptococcus pneumoniae & 10 & $9.8 \pm 1.0$ \\
Staphylococcus aureus & 10 & $9.0 \pm 0.8$ \\
Salmonella enterica & 10 & $9.3 \pm 0.5$ \\
\hline
\end{tabular}

Antimicrobial properties are more common for glycolipids or lipopeptides [62]. Most of the biosurfactants which possess antimicrobial properties have usually been produced from microorganisms isolated from contaminated and domestic sites [66]. Similarly, P. citronellolis $620 \mathrm{C}$ was isolated from a tank containing drilling waste.

The antimicrobial activity of BSs relies on the outer membrane of pathogens, which can be disrupted by the hydrophobic domain of the BSs, thus, breaking the structure of microorganisms and disabling pathogen activity. Therefore, the current BS has the potential to act as an alternative natural antibiotic, when tested against human cells. Furthermore, the current BS also has the potential to act as a disinfectant. Disinfectants are chemical means employed to inactivate pathogens, which are not inhibited anymore due to antimicrobial resistance [67]. Thus, further research on the toxicity of the BS to human skin and metabolic pathways is necessary to establish its antibiotic or disinfectant potential.

Although in recent years several studies on the antimicrobial activity of BSs have been performed, such studies are debated. This is because of the diversity of methodologies which have been employed to establish the activity and the different purity levels of the examined BSs. Upon use of the agar susceptibility method, Das et al., 2008a [62] provided a solution of the partially purified BS in methanol. The latter could be the main factor for bacterial pathogens lethality in that study. Furthermore, in other studies, the concentration of the BS used to determine antimicrobial activity was not mentioned, such as that of Ilori et al. (2008) [68]. Over recent years, materials and methods analysis of antimicrobial activity has become more detailed.

It has to be pointed out, that the majority of the studies found by the author exploit the antimicrobial activity of the purified BS acquired through the solvent extraction method described in Section 2.5. Therefore, biological activity can be attributed to the presence of several compounds, which may act synergistically, enabling antimicrobial action. Further purification of the BS may enhance antimicrobial properties. This is achieved through the exhaustive use of solvents and extraction steps [69] which, however, greatly increases the cost of the bioprocess, rendering down-stream processing unattractive. In the present study, the antimicrobial potential of the partially purified BS was examined, without further purification steps, leading to promising results and a promising, less-costly, down-stream processing method of the BS. However, further research on the purity, chemical structure and identification is necessary.

\subsection{MIC of the Biosurfactant}

The commonly used halo technique, using the agar disc diffusion method, was employed to determine the MIC of the BS (Table 2). The partially purified BS was extracted from the P. citronellolis $620 \mathrm{C}$ culture using $1 \%(v / v)$ DCF. The solution of the BS was able to inhibit bacterial growth in concentrations as low as $0.25 \mathrm{mg} / \mathrm{mL}$. K. pneumoniae was affected at such a low BS concentration. P. aeruginosa, E. coli resistant and E. coli were observed to be inhibited at a relatively higher BS concentration $(0.5 \mathrm{mg} / \mathrm{mL})$. The BS inhibited 
the E. faecalis and S. enterica at concentrations as low as $5 \mathrm{mg} / \mathrm{mL}$. However, in the agar plate of E. faecalis, only one out of four discs impregnated with BS solution showed an inhibition zone, resulting in a high SD (Table 2). Furthermore, A. baumaniii, S. pneumoniae and $S$. aureus were inhibited at relatively higher concentrations of $10 \mathrm{mg} / \mathrm{mL}$. It was noticed that the Gram-positive pathogens were more resilient and insensitive to the BS solution, compared to the Gram-negative strains. Specifically, at least five and in most cases 10 times more BS solution was needed to inhibit these multi-drug resistant bacteria. This could be attributed to their structure, whereby the cell wall is relatively harder to break, compared to that of the Gram-negative bacteria. Interestingly, a higher dose of the BS solution was essential to observe inhibition of the Gram-negative A. baumaniii, demonstrating the high resistance of the pathogen [70], but also the importance of the antimicrobial activity of the current BS, which can efficiently inhibit the growth of this emerging pathogen. The differences observed in the sensitivity of the pathogens to the BS do not only depend on the composition of the BS. The antimicrobial activity, except of the purity of the BS, may also be influenced by the nutritional and environmental conditions, and adaptation of the bacterial pathogens [71].

Table 2. Minimum inhibitory concentration (MIC) of the partially purified BS against multidrug-resistant pathogenic bacterial strains, using the agar susceptibility method.

\begin{tabular}{ccccccc}
\hline & & \multicolumn{5}{c}{ Antimicrobial Zone Diameter (mm) } \\
\hline Biosurfactant (mg/mL): & $\mathbf{1 0}$ & $\mathbf{5}$ & $\mathbf{1}$ & $\mathbf{0 . 5}$ & $\mathbf{0 . 2 5}$ & $\mathbf{0 . 1}$ \\
\hline Klebsiella pneumoniae & - & - & $9.0 \pm 0.7$ & $8.0 \pm 0.0$ & $7.0 \pm 0.0$ & $0.0 \pm 0.0$ \\
Pseudomonas aeruginosa & - & - & $8.8 \pm 0.8$ & $8.5 \pm 0.6$ & $0.0 \pm 0.0$ & $0.0 \pm 0.0$ \\
Escherichia coli resistant & - & - & $10.5 \pm 1.5$ & $7.3 \pm 0.5$ & $0.0 \pm 0.0$ & $0.0 \pm 0.0$ \\
Escherichia coli & - & - & $8.8 \pm 0.4$ & $0.0 \pm 0.0$ & $0.0 \pm 0.0$ & $0.0 \pm 0.0$ \\
Enterococcus faecalis resistant & $9.3 \pm 2.2$ & $0.0 \pm 0.0$ & $0.0 \pm 0.0$ & - & - & - \\
Enterococcus faecalis & $8.3 \pm 1.9$ & $1.8 \pm 3.5$ & $0.0 \pm 0.0$ & - & - & - \\
Acinetobacter baumaniii & $7.3 \pm 5.3$ & $0.0 \pm 0.0$ & $0.0 \pm 0.0$ & - & - & - \\
Streptococcus pneumoniae & $9.8 \pm 1.0$ & $0.0 \pm 0.0$ & $0.0 \pm 0.0$ & - & - & - \\
Staphylococcus aureus & $9.0 \pm 0.8$ & $0.0 \pm 0.0$ & $0.0 \pm 0.0$ & - & - & - \\
Salmonella enterica & $9.3 \pm 0.5$ & $8.3 \pm 1.9$ & $0.0 \pm 0.0$ & - & - & -
\end{tabular}

MIC may be performed for highly pure BSs, such as rhamnolipids, reaching $99 \%$ purity [64]. Despite the purity level, the inhibition zone observed against E. coli, S. aureus and S. enterica is similar to that of the current study. The inhibition zone against $E$. coli strains was also similar to other studies such as Onbasli \& Aslim (2008) [72].

\section{Conclusions}

In the current study, (i) a novel BS-producing microorganism was isolated from a waste site, (ii) BS formation was a result of DW biodegradation, (iii) an optimization strategy of BS production was explored through supplementation of iron forms, which led to a great production enhancement upon induction with $0.1 \mathrm{mM}$. Among $\mathrm{FeSO}_{4}, \mathrm{FeCl}_{3}$ and $\mathrm{Fe}\left(\mathrm{NO}_{3}\right)_{3}$, addition of $\mathrm{FeCl}_{3}$ resulted in the highest increase in both BS, microbial growth and DW biodegradation. Use of a waste stream as substrate may result in a significant reduction in the bioprocess cost. The partially purified BS has promising antimicrobial potential against several Gram-negative and -positive multi-drug resistant bacterial pathogens. Hence, as no extra purification steps are necessary, a reduction in down-stream processing costs is possible. Preliminary characterization of the aforementioned BS via a number of analytical methods established its thermostability, low crystallinity and the presence of a peptide structure. The BS hereby produced and studied appears to have great potential in biomedical and environmental biotechnological applications. 
Supplementary Materials: The following are available online at https://www.mdpi.com/article/10 $.3390 / \mathrm{pr} 9040686 / \mathrm{s} 1$, Figure S1: Bacterial growth and \% COD removal upon biodegradation of 5 and $10 \%(v / v)$ DCF, Table S1: Top 10 hits of the BLAST results.

Author Contributions: A.T.: conceptualization, methodology, investigation, experimentation, validation, writing original manuscript, reviewing, editing. K.S.: methodology, investigation, experimentation for extraction of the BS, iron forms effect, antimicrobial properties of BS. M.P.: methodology, investigation, experimentation for extraction of the BS, iron forms effect. L.K.: methodology, TGA/DTA analysis. I.R.: methodology, XRD analysis, reviewing and editing of the manuscript. I.I.: methodology, TGA/DTA and XRD analysis, reviewing and editing of the manuscript. E.P. (Erato Papageorgiou): methodology, FTIR analysis. E.P. (Eftychia Pinakoulaki): methodology, FTIR analysis, writing of FTIR results, reviewing and editing of the manuscript. All authors have read and agreed to the published version of the manuscript.

Funding: This research was funded by University of Cyprus, Cyprus. The APC was funded by the Department of Civil and Environmental Engineering, University of Cyprus, Cyprus.

Institutional Review Board Statement: Not applicable.

Informed Consent Statement: Not applicable.

Data Availability Statement: Data available on request due to privacy restrictions. The data presented in this study are available on request from the corresponding author.

Acknowledgments: The corresponding author would like to thank IESC Ltd. (Limassol, Cyprus) for providing the drilling waste. Furthermore, the corresponding author would like to thank researcher Anna Korelidou for providing the multi-drug resistant strains isolated from the municipal wastewater treatment of Limassol and the University of Cyprus for financial support.

Conflicts of Interest: The authors declare no conflict of interest.

\section{References}

1. Hemlata, B.; Selvin, J.; Tukaram, K. Optimization of iron chelating biosurfactant production by Stenotrophomonas maltophilia NBS-11. Biocatal. Agric. Biotechnol. 2015, 4, 135-143. [CrossRef]

2. Liu, J.; Vipulanandan, C.; Cooper, T.F.; Vipulanandan, G. Effects of Fe nanoparticles on bacterial growth and biosurfactant production. J. Nanoparticle Res. 2013, 15, 1-13. [CrossRef]

3. Banat, I.M.; Makkar, R.S.; Cameotra, S.S. Potential commercial applications of microbial surfactants. Appl. Microbiol. Biotechnol. 2000, 53, 495-508. [CrossRef]

4. Naughton, P.; Marchant, R.; Naughton, V.; Banat, I. Microbial biosurfactants: Current trends and applications in agricultural and biomedical industries. J. Appl. Microbiol. 2019, 127, 12-28. [CrossRef] [PubMed]

5. Dhiman, R.; Meena, K.R.; Sharma, A.; Kanwar, S.S. Biosurfactants and their Screening Methods Biosurfactants and their Screening Methods. Res. J. Recent Sci. 2016, 5, 1-6.

6. Shekhar, S.; Sundaramanickam, A.; Balasubramanian, T. Biosurfactant Producing Microbes and their Potential Applications: A Review. Crit. Rev. Environ. Sci. Technol. 2015, 45, 1522-1554. [CrossRef]

7. Markande, A.R.; Patel, D.; Varjani, S. A review on biosurfactants: Properties, applications and current developments. Bioresour. Technol. 2021, 330, 124963. [CrossRef] [PubMed]

8. Smith, M.L.; Gandolfi, S.; Coshall, P.M.; Rahman, P.K.S.M. Biosurfactants: A Covid-19 Perspective. Front. Microbiol. 2020, $11,1341$. [CrossRef] [PubMed]

9. Franzetti, A.; Gandolfi, I.; Bestetti, G.; Smyth, T.J.P.; Banat, I.M. Production and applications of trehalose lipid biosurfactants. Eur. J. Lipid Sci. Technol. 2010, 112, 617-627. [CrossRef]

10. Kaskatepe, B.; Yildiz, S. Rhamnolipid Biosurfactants Produced by Pseudomonas Species. Braz. Arch. Biol. Technol. 2016, 59, 1-16. [CrossRef]

11. Jimoh, A.A.; Lin, J. Biosurfactant: A new frontier for greener technology and environmental sustainability. Ecotoxicol. Environ. Saf. 2019, 184, 109607. [CrossRef] [PubMed]

12. Santos, D.K.; Rufino, R.D.; Luna, J.M.; Santos, V.A.; Salgueiro, A.A.; Sarubbo, L.A. Synthesis and evaluation of biosurfactant produced by Candida lipolytica using animal fat and corn steep liquor. J. Pet. Sci. Eng. 2013, 105, 43-50. [CrossRef]

13. Onwukwe, S.I.; Nwakaudu, M.S. Drilling Wastes Generation and Management Approach. Int. J. Environ. Sci. Dev. 2012, 3, 252-257. [CrossRef]

14. Karlapudi, A.P.; Venkateswarulu, T.; Tammineedi, J.; Kanumuri, L.; Ravuru, B.K.; Dirisala, V.R.; Kodali, V.P. Role of biosurfactants in bioremediation of oil pollution-a review. Petroleum 2018, 4, 241-249. [CrossRef]

15. Yan, P.; Lu, M.; Yang, Q.; Zhang, H.-L.; Zhang, Z.-Z.; Chen, R. Oil recovery from refinery oily sludge using a rhamnolipid biosurfactant-producing Pseudomonas. Bioresour. Technol. 2012, 116, 24-28. [CrossRef] 
16. Elshafie, A.E.; Joshi, S.J.; Al-Wahaibi, Y.M.; Al-Bemani, A.S.; Al-Bahry, S.N.; Al-Maqbali, D.; Banat, I.M. Sophorolipids Production by Candida bombicola ATCC 22214 and its Potential Application in Microbial Enhanced Oil Recovery. Front. Microbiol. 2015, 6, 1324. [CrossRef]

17. Datta, P.; Tiwari, P.; Pandey, L.M. Isolation and characterization of biosurfactant producing and oil degrading Bacillus subtilis MG495086 from formation water of Assam oil reservoir and its suitability for enhanced oil recovery. Bioresour. Technol. 2018, 270, 439-448. [CrossRef]

18. Kiran, G.S.; Nishanth, L.A.; Priyadharshini, S.; Anitha, K.; Selvin, J. Effect of Fe nanoparticle on growth and glycolipid biosurfactant production under solid state culture by marine Nocardiopsissp. MSA13A. BMC Biotechnol. 2014, 14, 48. [CrossRef] [PubMed]

19. Jimoh, A.A.; Lin, J. Enhancement of Paenibacillus sp. D9 Lipopeptide Biosurfactant Production Through the Optimization of Medium Composition and Its Application for Biodegradation of Hydrophobic Pollutants. Appl. Biochem. Biotechnol. 2019, 187, 724-743. [CrossRef]

20. Haferburg, G.; Kothe, E. Microbes and metals: Interactions in the environment. J. Basic Microbiol. 2007, 47, 453-467. [CrossRef] [PubMed]

21. Sambrook, J.; Fritsch, E.F.; Maniatis, E. Molecular Cloning: A Laboratory Manual; Cold Spring Harbour Press: Cold Spring Harbor, NY, USA, 1989.

22. Suryanti, V.; Marliyana, S.D.; Handayani, D.S.; Ratnaningrum, D. Production and characterization of biosurfactant by pseudomonas fluorescens using cassava flour wastewater as media. Indones. J. Chem. 2013, 13, 229-235. [CrossRef]

23. De Rienzo, M.A.D.; Stevenson, P.; Marchant, R.; Banat, I.M. Antibacterial properties of biosurfactants against selected Grampositive and -negative bacteria. FEMS Microbiol. Lett. 2016, 363, fnv224. [CrossRef] [PubMed]

24. Desai, J.D.; Banat, I.M. Microbial production of surfactants and their commercial potential. Microbiol. Mol. Biol. Rev. 1997, 61, 47-64. [CrossRef]

25. Huck-Iriart, C.; De-Candia, A.; Rodriguez, J.; Rinaldi, C. Determination of Surface Tension of Surfactant Solutions through Capillary Rise Measurements: An Image-Processing Undergraduate Laboratory Experiment. J. Chem. Educ. 2016, 93, 1647-1651. [CrossRef]

26. Eldin, A.M.; Kamel, Z.; Hossam, N. Isolation and genetic identification of yeast producing biosurfactants, evaluated by different screening methods. Microchem. J. 2019, 146, 309-314. [CrossRef]

27. Wang, Q.; Fang, X.; Bai, B.; Liang, X.; Shuler, P.J.; Iii, W.A.G.; Tang, Y. Engineering bacteria for production of rhamnolipid as an agent for enhanced oil recovery. Biotechnol. Bioeng. 2007, 98, 842-853. [CrossRef] [PubMed]

28. Remus-Emsermann, M.N.; Schmid, M.; Gekenidis, M.-T.; Pelludat, C.; Frey, J.E.; Ahrens, C.H.; Drissner, D. Complete genome sequence of Pseudomonas citronellolis P3B5, a candidate for microbial phyllo-remediation of hydrocarbon-contaminated sites. Stand. Genom. Sci. 2016, 11, 1-12. [CrossRef] [PubMed]

29. Zheng, D.; Wang, X.; Wang, P.; Peng, W.; Ji, N.; Liang, R. Genome Sequence of Pseudomonas citronellolis SJTE-3, an Estrogenand Polycyclic Aromatic Hydrocarbon-Degrading Bacterium. Genome Announc. 2016, 4, 16-17. [CrossRef] [PubMed]

30. Oso, S.; Walters, M.; Schlechter, R.O.; Remus-Emsermann, M.N.P. Utilisation of hydrocarbons and production of surfactants by bacteria isolated from plant leaf surfaces. FEMS Microbiol. Lett. 2019, 366, 1-10. [CrossRef]

31. Singh, P.; Tiwary, B.N. Isolation and characterization of glycolipid biosurfactant produced by a Pseudomonas otitidis strain isolated from Chirimiri coal mines, India. Bioresour. Bioprocess. 2016, 3, 42. [CrossRef]

32. Ron, E.Z.; Rosenberg, E. Biosurfactants and oil bioremediation. Curr. Opin. Biotechnol. 2002, 13, 249-252. [CrossRef]

33. Haidar, C.N.; Pereira, M.M.; Lima, Á.S.; Nerli, B.B.; Malpiedi, L.P. Biosurfactants produced by Pseudomonas syringae pv tabaci: A versatile mixture with interesting emulsifying properties. Process. Biochem. 2020, 97, 121-129. [CrossRef]

34. Meliani, A. Enhancement of Hydrocarbons Degradation by Use of Pseudomonas Biosurfactants and Biofilms. J. Pet. Environ. Biotechnol. 2014, 05, 1-7. [CrossRef]

35. Rosenberg, E.; Ron, E.Z. Biosurfactants. In The Prokaryotes: Applied Bacteriology and Biotechnology; Rosenberg, E.F., DeLong, S., Lory, E., Stackebrandt, F., Thompson, E., Eds.; Springer: Berlin/Heidelberg, Germany, 2013; pp. 281-294. [CrossRef]

36. Abouseoud, M.; Maachi, R.; Amrane, A.; Boudergua, S.; Nabi, A. Evaluation of different carbon and nitrogen sources in production of biosurfactant by Pseudomonas fluorescens. Desalination 2008, 223, 143-151. [CrossRef]

37. Bak, F.; Bonnichsen, L.; Jørgensen, N.O.G.; Nicolaisen, M.H.; Nybroe, O. The biosurfactant viscosin transiently stimulates n-hexadecane mineralization by a bacterial consortium. Appl. Microbiol. Biotechnol. 2015, 99, 1475-1483. [CrossRef]

38. Ismail Isa, T.; Ngoshe, I.Y.; Gajere, H.M. Biosurfactant Production by Bacteria Isolated from Hydrocarbon-impacted soil. Bioremed. Sci. Technol. Res. 2019, 6, 4-8.

39. Jacques, R.J.S.; Santos, E.C.; Haddad, R.; Catharino, R.R.; Eberlin, M.N.; Bento, F.M.; Camargo, F.A.D.O. Mass spectrometry analysis of surface tension reducing substances produced by a pah-degrading Pseudomonas citronellolis strain. Braz. J. Microbiol. 2008, 39, 353-356. [CrossRef]

40. Santos, E.C.; Jacques, R.J.; Bento, F.M.; Peralba, M.D.C.R.; Selbach, P.A.; Sá, E.L.; Camargo, F.A. Anthracene biodegradation and surface activity by an iron-stimulated Pseudomonas sp. Bioresour. Technol. 2008, 99, 2644-2649. [CrossRef]

41. Wei, Y.-H.; Wang, L.-F.; Changy, J.-S.; Kung, S.-S. Identification of induced acidification in iron-enriched cultures of Bacillus subtilis during biosurfactant fermentation. J. Biosci. Bioeng. 2003, 96, 174-178. [CrossRef] 
42. Andrews, S.C.; Robinson, A.K.; Rodríguez-Quiṽones, F. Bacterial iron homeostasis. FEMS Microbiol. Rev. $2003,27,215-237$. [CrossRef]

43. Dinkla, I.J.T.; Gabor, E.M.; Janssen, D.B. Effects of Iron Limitation on the Degradation of Toluene by Pseudomonas Strains Carrying the TOL (pWWO) Plasmid. Appl. Environ. Microbiol. 2001, 67, 3406-3412. [CrossRef]

44. Dinkla, I.; Janssen, D. Simultaneous Growth on Citrate Reduces the Effects of Iron Limitation during Toluene Degradation in Pseudomonas. Microb. Ecol. 2003, 45, 97-107. [CrossRef]

45. Wei, Y.-H.; Chu, I.-M. Enhancement of surfactin production in iron-enriched media by bacillus subtilis ATCC 21332. Enzym. Microb. Technol. 1998, 22, 724-728. [CrossRef]

46. Makkar, S.C.R. An update on the use of unconventional substrates for biosurfactant production and their new applications. Appl. Microbiol. Biotechnol. 2002, 58, 428-434. [CrossRef]

47. Kiran, G.S.; Thomas, T.A.; Selvin, J. Production of a new glycolipid biosurfactant from marine Nocardiopsis lucentensis MSA04 in solid-state cultivation. Colloids Surf. B Biointerfaces 2010, 78, 8-16. [CrossRef]

48. Dunham, N.P.; Arnold, F.H. Nature's Machinery, Repurposed: Expanding the Repertoire of Iron-Dependent Oxygenases. ACS Catal. 2020, 10, 12239-12255. [CrossRef]

49. Ismail, A.R.; Alias, A.H.; Sulaiman, W.R.W.; Jaafar, M.Z.; Ismail, I. Drilling fluid waste management in drilling for oil and gas wells. Chem. Eng. Trans. 2017, 56, 1351-1356. [CrossRef]

50. De Almeida, D.G.; Silva, R.D.C.F.S.D.; Luna, J.M.; Rufino, R.D.; Santos, V.A.; Banat, I.M.; Sarubbo, L.A. Biosurfactants: Promising Molecules for Petroleum Biotechnology Advances. Front. Microbiol. 2016, 7, 1718. [CrossRef] [PubMed]

51. Barth, A. Infrared spectroscopy of proteins. Biochim. Biophys. Acta (BBA) Bioenerg. 2007, 1767, 1073-1101. [CrossRef] [PubMed]

52. Moldes, A.B.; Paradelo, R.; Vecino, X.; Cruz, J.M.; Gudiña, E.; Rodrigues, L.; Teixeira, J.A.; Domínguez, J.M.; Barral, M.T. Partial Characterization of Biosurfactant fromLactobacillus pentosusand Comparison with Sodium Dodecyl Sulphate for the Bioremediation of Hydrocarbon Contaminated Soil. BioMed Res. Int. 2013, 2013, 1-6. [CrossRef] [PubMed]

53. Derenne, A.; Derfoufi, K.-M.; Cowper, B.; Delporte, C.; Goormaghtigh, E. FTIR spectroscopy as an analytical tool to compare glycosylation in therapeutic monoclonal antibodies. Anal. Chim. Acta 2020, 1112, 62-71. [CrossRef] [PubMed]

54. Krilov, D.; Balarin, M.; Kosovic, M.; Gamulin, O.; Brnjas-Kraljević, J. FT-IR spectroscopy of lipoproteins-A comparative study. Spectrochim. Acta Part A: Mol. Biomol. Spectrosc. 2009, 73, 701-706. [CrossRef] [PubMed]

55. Kiran, G.S.; Priyadharsini, S.; Sajayan, A.; Priyadharsini, G.B.; Poulose, N.; Selvin, J. Production of Lipopeptide Biosurfactant by a Marine Nesterenkonia sp. and Its Application in Food Industry. Front. Microbiol. 2017, 8, 1138. [CrossRef] [PubMed]

56. Chandankere, R.; Yao, J.; Cai, M.; Masakorala, K.; Jain, A.; Choi, M.M. Properties and characterization of biosurfactant in crude oil biodegradation by bacterium Bacillus methylotrophicus USTBa. Fuel 2014, 122, 140-148. [CrossRef]

57. Kourmentza, C.; Costa, J.; Azevedo, Z.; Servin, C.; Grandfils, C.; De Freitas, V.; Reis, M. Burkholderia thailandensis as a microbial cell factory for the bioconversion of used cooking oil to polyhydroxyalkanoates and rhamnolipids. Bioresour. Technol. 2018, 247, 829-837. [CrossRef]

58. Weiss, I.M.; Muth, C.; Drumm, R.; Kirchner, H.O.K. Thermal decomposition of the amino acids glycine, cysteine, aspartic acid, asparagine, glutamic acid, glutamine, arginine and histidine. BMC Biophys. 2018, 11, 1-15. [CrossRef]

59. Reeves, C.J.; Menezes, P.L.; Jen, T.-C.; Lovell, M.R. The influence of fatty acids on tribological and thermal properties of natural oils as sustainable biolubricants. Tribol. Int. 2015, 90, 123-134. [CrossRef]

60. Saranya, P.; Swarnalatha, S.; Sekaran, G. Lipoprotein biosurfactant production from an extreme acidophile using fish oil and its immobilization in nanoporous activated carbon for the removal of Ca2+and Cr3+in aqueous solution. RSC Adv. 2014, 4, 34144-34155. [CrossRef]

61. Hutchinson, J.A.; Hamley, I.W.; Torras, J.; Alemán, C.; Seitsonen, J.; Ruokolainen, J. Self-Assembly of Lipopeptides Containing Short Peptide Fragments Derived from the Gastrointestinal Hormone PYY3-36: From Micelles to Amyloid Fibrils. J. Phys. Chem. B 2019, 123, 614-621. [CrossRef] [PubMed]

62. Das, P.; Mukherjee, S.; Sen, R. Antimicrobial potential of a lipopeptide biosurfactant derived from a marine Bacillus circulans. J. Appl. Microbiol. 2008, 104, 1675-1684. [CrossRef]

63. Ndlovu, T.; Rautenbach, M.; Vosloo, J.A.; Khan, S.; Khan, W. Characterisation and antimicrobial activity of biosurfactant extracts produced by Bacillus amyloliquefaciens and Pseudomonas aeruginosa isolated from a wastewater treatment plant. AMB Express 2017, 7, 1-19. [CrossRef] [PubMed]

64. Ferreira, J.D.F.; Vieira, E.A.; Nitschke, M. The antibacterial activity of rhamnolipid biosurfactant is pH dependent. Food Res. Int 2019, 116, 737-744. [CrossRef]

65. Karlapudi, A.P.; T.C., V.; Srirama, K.; Kota, R.K.; Mikkili, I.; Kodali, V.P. Evaluation of anti-cancer, anti-microbial and anti-biofilm potential of biosurfactant extracted from an Acinetobacter M6 strain. J. King Saud Univ. Sci. 2020, 32, 223-227. [CrossRef]

66. Das, P.; Mukherjee, S.; Sen, R. Genetic Regulations of the Biosynthesis of Microbial Surfactants: An Overview. Biotechnol. Genet. Eng. Rev. 2008, 25, 165-186. [CrossRef] [PubMed]

67. Singh, A.K.; Sharma, P. Disinfectant-like activity of lipopeptide biosurfactant produced by Bacillus tequilensis strain SDS21. Colloids Surfaces B: Biointerfaces 2020, 185, 110514. [CrossRef]

68. Ilori, M.O.; Adebusoye, S.A.; Ojo, A.C. Isolation and characterization of hydrocarbon-degrading and biosurfactant-producing yeast strains obtained from a polluted lagoon water. World J. Microbiol. Biotechnol. 2008, 24, 2539-2545. [CrossRef] 
69. Tang, Y.; Ma, Q.; Du, Y.; Ren, L.; Van Zyl, L.J.; Long, X. Efficient purification of sophorolipids via chemical modifications coupled with extractions and their potential applications as antibacterial agents. Sep. Purif. Technol. 2020, 245, 116897. [CrossRef]

70. Howard, A.; O’Donoghue, M.; Feeney, A.; Sleator, R.D. Acinetobacter baumannii. Virulence 2012, 3, 243-250. [CrossRef]

71. Otzen, D.E. Biosurfactants and surfactants interacting with membranes and proteins: Same but different? Biochim. Biophys. Acta (BBA) Biomembr. 2017, 1859, 639-649. [CrossRef]

72. Onbasli, D.; Aslim, B. Determination of antimicrobial activity and production of some metabolites by Pseudomonas aeruginosa B1 and B2 in sugar beet molasses. Afr. J. Biotechnol. 2008, 7, 4614-4619. 